\title{
Evaluation of the association of SNP in carboxylesterase enzyme (CES1) with pharmacokinetic and adverse effects of capecitabine in breast and colorectal cancer patients
}

\author{
Merve Kurtan Yüksel ${ }^{1}$ (D), Dilek Öztürk ${ }^{2}$ (D), Ezgi Öztaş ${ }^{3}$ (D), Gül Özhan ${ }^{3}$ (D), Aylin Altanlar Türker ${ }^{4}$ (D), \\ Taner Korkmaz ${ }^{5}$ (D), Alper Okyar ${ }^{1}$ (D), Zeliha Pala Kara' (1) \\ 'Department of Pharmacology, İstanbul University, Faculty of Pharmacy, Beyazit, 34116, İstanbul, Turkey \\ 2Department of Pharmacology, Bezmialem Vakif University, Faculty of Pharmacy, Fatih, 34093, İstanbul, Turkey \\ ${ }^{3}$ Department of Pharmaceutical Toxicology, İstanbul University, Faculty of Pharmacy, Beyazit, 34116, İstanbul, Turkey \\ ${ }^{4}$ Acibadem Mehmet Ali Aydınlar University, Pharmacy Services, 34457, İstanbul, Turkey \\ ${ }^{5}$ Department of Medical Oncology, Acibadem Mehmet Ali Aydınlar University, Maslak Hospital, 34457, İstanbul, Turkey
}

ORCID IDs of the authors: M.K.Y. 0000-0003-0715-7409; D.Ö. 0000-0003-2485-891X; E.0̈. 0000-0002-0718-2359; G.0̈. 00000002-6926-5723; A.A.T. 0000-0002-9221-6866; T.K. 0000-0003-4292-0545; A.0. 0000-0002-9891-5588; Z.P.K. 0000-0001-78985602.

Cite this article as: Kurtan Yüksel M, Öztürk D, Öztaş E, Özhan G, Altanlar Türker A, Korkmaz T, Okyar A, Pala Kara Z (2019). Evaluation of the association of SNP in carboxylesterase enzyme (CES1) with pharmacokinetic and adverse effects of capecitabine in breast and colorectal cancer patients. Istanbul J Pharm 49 (2): 64-69.

\begin{abstract}
Capecitabine is an oral prodrug and converted to 5 -fluorouracil using three-step enzymatic pathways which include carboxylesterase (CES). Interindividual differences in the activities of drug-metabolizing enzymes may affect efficacy and toxicity. The aim of this study is to evaluate the association of Single nucleotide polymorphisms (SNP) in CES1 with the pharmacokinetic and adverse effects of capecitabine. Plasma samples were obtained from 7 breast and colorectal cancer patients who were treated with capecitabine-based chemotherapy $\left(1000-1250 \mathrm{mg} / \mathrm{m}^{2}\right)$ at $0.5,1,2,3$ and 4 hours following drug administration on their first day of the first cycle. The plasma concentrations of the capecitabine were determined by using a high-pressure liquid chromatography-UV detector. SNP (rs8192950) was genotyped using the reverse transcription-polymerase chain reaction. Patients were found to have heterozygote $(57 \%)$, wild $(29 \%)$, and mutant $(14 \%)$ distributions of genotypes ( $p=0.909)$. The mean plasma area under the curve $\left(A \cup C_{0-4 \mathrm{~h}}\right.$ ) was $4.60 \pm 2.25 \mu \mathrm{g} . \mathrm{h} / \mathrm{mL}$, and maximum plasma concentration $\left(\mathrm{C}_{\max }\right)$ was $3.19 \pm 2.5$ $\mu \mathrm{g} / \mathrm{mL}$. There were no statistically significant differences between genotypes and AUC values ( $p=0.2236)$ and the most frequently observed side effects were diarrhea $(p=0.1028)$, asthenia $(p=0.6456)$, anemia $(p=0.6456)$, emesis ( $p=0.3499)$. This is the first study evaluating an association of genetic variation in CES1 (rs8192950) with pharmacokinetic and adverse effects of capecitabine. Therefore, additional study in larger groups of patients is required to support our study.
\end{abstract}

Keywords: Capecitabine, carboxylesterase, pharmacogenetics, breast cancer, colorectal cancer

\section{INTRODUCTION}

Cancer is a major worldwide public health concern and is the second leading cause of death in the world with colorectal and breast cancer being among the most common cancers in the world (Siegel et al. 2019). Breast cancer is the most common type of cancer and the leading cause of cancer related deaths in women while colorectal cancer is the third most common cancer among women and men in Turkey (TC Ministry of Health Turkey Cancer Statistics 2018).

Capecitabine is used orally in the treatment of breast, colorectal and gastric cancer. Capecitabine is a precursor and converted to 5-fluorouracil (5-FU) (which is a cytotoxic agent) in the tumor. 5-FU is one of the oldest and the most widely used antimetabolite and cytotoxic agents (Reigner et al. 2001). 
Capecitabine is extensively metabolized to 5-FU using threestep enzymatic pathways. After oral administration, it is converted into 5'-deoxy-5-fluorocytidine (5'-DFCR) in the liver by carboxylesterase (CES). The $5^{\prime}$-DFCR is then converted to 5'-deoxy-5-fluorouridine (5'-DFUR) by cytidine deaminase (CDA) which is found in the liver and tumor tissues. 5-FU formation occurs on the tumor area with a basis of thymidine phosphorylase (TYMP) and it minimizes the systemic exposure of 5-FU to healthy body tissue. Capecitabine becomes cytotoxic after conversion to 5-FU and its metabolites. 5-FU is catabolized by dihydropyrimidine dehydrogenase (DPYD) and transforms to the inactive metabolites dihydro-5-fluorouracil $\left(\mathrm{FUH}_{2}\right)$, 5-fluoro-ureido propionic acid (FUPA) and a-fluoro- $\beta$-alanine (FBAL) (Reigner et al. 2001; Thorn et al. 2011; Daniele et al. 2013). Dose limiting toxicities of capecitabine include diarrhoea, abdominal pain, nausea, stomatitis and hand-foot syndrome (hand-foot skin reaction, palmar-plantar erythrodysesthesia) (Xeloda Roche $500 \mathrm{mg}$ Summary of Product Characteristics). Pharmacokinetics, efficacy and adverse effects incidence from using oral capecitabine also are vary in individuals in the treatment of breast and colorectal cancer when administered as a monotherapy or combination therapy. Expression differences of enzymes involved in the metabolism of capecitabine may be the reason in the interindividuals'variation (Reigner et al. 2001; Thorn et al. 2011).

Mammalian carboxylesterases (CEs) are key enzymes from the serine hydrolase superfamily. Two carboxylesterases (CES1 and CES2) have been identified in the human body and extensively studied over the past decade. CES1 are expressed mainly in the liver while CES2 mostly in the intestine. The key roles of CES are xenobiotic and drug metabolism. To date, a number of functional genetic variants of CES1 and CES2 have been reported, which may be associated with substantial individual variations in the responses to pharmacologic therapies (Wang D et al. 2018). It has been found that is an association between efficacy of CES enzymes substrates such as clopidogrel (Lewis et al. 2013; Zhao et al. 2016; Xiao et al. 2017), dabigatran (Pare et al. 2013), enalapril (Tarkiainen et al. 2015), imidapril (Geshi et al. 2005), oseltamivir (Tarkiainen et al. 2012) and CES polymorphisms. It has been shown that polymorphisms in the enzyme CES 2 (Ribelles et al. 2008; Martin et al. 2015) and CES 1 (Hamzic et al. 2017) altered the efficacy and toxicity of capecitabine but no pharmacokinetic evaluation has been made. In this study, the association of SNP (rs8192950) in CES1 (which metabolizes capecitabine to $5^{\prime}$-DFCR), with the pharmacokinetic and adverse effects of capecitabine were analyzed.

\section{MATERIALS AND METHODS}

\section{Study Protocol}

A routine standard chemotherapy regimen (which uses capecitabine) was administered to the patients who signed the voluntary informed consent form in Acibadem Maslak Hospital Oncology Clinic, Istanbul, Turkey. Patients meeting the inclusion criteria and enrolling in the study received capecitabine at 1000-1250 mg/m², perorally twice daily for 14 days followed by a 7-day rest period, over a total of 6 months. Blood samples (5 $\mathrm{mL}$ ) were collected for genotype analysis in EDTA coated tubes on day 1 of the first cycle before capecitabine application. Dur- ing the same day, genomic DNA was isolated from whole blood for further analysis of the genetic variants and stored at $-80^{\circ} \mathrm{C}$. Blood samples ( $3 \mathrm{~mL}$ ) were taken for pharmacokinetic analysis at $0.5,1,2,3$ and 4 hours after capecitabine application on day 1 of the first cycle. The blood samples in the tetrahydrouridine tube were centrifuged immediately (10 minutes, 3000 rpm) and the plasma was stored at $-80^{\circ} \mathrm{C}$ for later analysis.

All patients provided informed consent, and the study was conducted after ethical approval (Approval No: ATADEK 2015/9) which was provided by the Ethical Committee of Acibadem University Hospitals (ATADEK), Istanbul, Turkey).

\section{Inclusion criteria}

- Histopathologic diagnosis of breast or colon adenocarcinoma,

- Patients who had received neoadjuvant and/or adjuvant treatment for more than 6 months before,

- Adults $>18$ years of age,

- Appropriate ECOG performance status (0-2),

- Patients without a prior history of severe cardiac problems (coronary artery disease, congestive heart failure, arrhythmia, etc). Normal kidney, liver and bone marrow functions.

- Ability to understand and sign a written informed consent form, which must be obtained prior to the initiation of the study procedure.

\section{Exclusion criteria}

- Pregnant or breastfeeding women,

- Patients who refuse to use an acceptable contraception method at reproductive age,

- Diagnosis of active gastrointestinal malabsorption and/or patients with enteral nutrition (jejunostomy),

- Experience of toxicity above the second degree in previous adjuvant or neoadjuvant therapy according to the CTCAE Version 4.0 (National Cancer Institute, USA, 2010),

- Abnormal liver or kidney functions,

- Patients who have a known DPD deficiency,

- Patients who have a known or symptomatic brain metastasis,

- Diagnosis of a systemic disease (uncontrolled diabetes, congestive heart failure, etc.),

- Concomitant administration of drugs which are metabolized by the CYP2C9 enzyme system (warfarin, phenytoin, etc.),

- Patients who had undergone major surgical procedures within the last 4 weeks,

- Patients who had received radiotherapy within the last 4 weeks,

- Patients who had a known allergic reaction to capecitabine and 5-FU.

\section{Evaluation of Side Effects}

The evaluation of side effects and the collection of the demographic and clinical data were managed by an oncologist. The adverse effects recorded included anemia, abdominal pain, nausea, diarrhea, stomatitis and hand-foot syndrome. Toxicity was graded according to the CTCAE version 4.0 of the National Cancer Institute and toxicity due to capecitabine administration was managed by symptomatic treatment and/or modification of the dose (treatment interruption or dose reduction). 


\section{Pharmacokinetic Analysis}

\section{Analytical Method}

Quantification of capecitabine in plasma was performed using a validated, sensitive and selective high-pressure liquid chromatography (HPLC) method which was used by Farkouh et al. (Farkouh et al. 2010). The capecitabine was provided by BioChemPartner (CAS No. 154361-50-9). Methanol Merck, Germany) and water (Milli Q-Millipore, USA) were HPLC grade. The analyses were performed on an HPLC system consisting of a Waters 2695 pump, autosampler, column heater, and Waters 2487 ultraviolet/visible (UV/SIS) detector (Waters, USA). The chromatographic conditions for the quantification of capecitabine in plasma are shown in Table 1.

\section{Extraction}

The matrix components were removed from the plasma samples by solid-phase extraction (Oasis 1 cc/30 mg; Waters, USA). After washing the cartridges for preconditioning with methanol $(1 \mathrm{~mL})$ and water $(1 \mathrm{~mL})$ the plasma sample $(1 \mathrm{~mL})$ was applied to the cartridge. After washing-out the matrix components with $5 \%$ methanol $(1 \mathrm{~mL})$, the capecitabine was eluted from the cartridge with methanol $(1 \mathrm{~mL})$.

\section{Calculation of Pharmacokinetic Parameters}

In order to determine the concentrations of capecitabine in the plasma samples, the peak areas in the chromatogram were used and the calibration curve was obtained using the following equation: $y=a x+b$. The calibration curve was linear within the range of $10-0.306 \mu \mathrm{g} / \mathrm{mL}$. The capecitabine plasma concentration time curve between 0 and 4 hours ( $t=0$ and $t=4 h$ ) was obtained using the GraphPad Prism 6. The area under the plasma concentration-time curve from 0 to 4 hours $\left(\mathrm{AUC}_{0-4 \mathrm{~h}}\right.$ )

\section{Table 1. The chromatographic conditions for quantification of capecitabine in plasma}

\begin{tabular}{|c|c|}
\hline Column & $\begin{array}{l}\text { Phenomenex }{ }^{\circledR} 250 \mathrm{~mm} \times 4 \mathrm{~mm}(5 \mu \mathrm{m}) \\
\text { C18 column }\end{array}$ \\
\hline Guard column & Phenomenex® $2.1 \times 3.9 \mathrm{~mm}$ C18 column \\
\hline Mobile phase & Methanol : water = 50:50 (v:v) \\
\hline Flow rate & $0.6 \mathrm{~mL} / \mathrm{min}$ \\
\hline $\begin{array}{l}\text { Column } \\
\text { temperature }\end{array}$ & $36^{\circ} \mathrm{C}$ \\
\hline Injection volume & $30 \mu \mathrm{L}$ \\
\hline Detection & 2487 dual wavelength UV/VIS detector \\
\hline Wavelength & $305 \mathrm{~nm}$ \\
\hline Retention time & $20 \mathrm{~min}$ \\
\hline Extraction & $\begin{array}{l}\text { SPE Cartridges (Oasis } ® 1 \mathrm{cc} / 30 \mathrm{mg} \text {; } \\
\text { Waters, USA) }\end{array}$ \\
\hline
\end{tabular}

was calculated using the trapezoidal method. The $C_{\max }$ and $t_{\text {max }}$ values were calculated using the plasma concentration time curve. The elimination rate constant $\left(k_{e}\right)$ was calculated from the terminal points of the cepecitabine plasma concentrationtime plot and the slope of this line was equal to $k_{e l}$. The terminal elimination half-life $\left(t_{1 / 2}\right)$ was calculated using log-linear approximation of the terminal points of the data. The terminal elimination half-life and elimination rate constant $\left(k_{e}\right)$ were interconverted with the following formula: $t_{1 / 2}=\ln 2 / k_{\mathrm{el}}$

\section{Genotyping}

Genomic DNA was extracted from whole blood using the standard phenol chloroform extraction protocol and further purification was done using High Pure PCR Product Purification Kit (Roche 11796828001; Roche, Mannheim, Germany). SNP analysis was performed using a LightCycler FastStart DNA Master HybProbe (Roche, Mannheim, Germany) and custom-designed LightSNiP assay probes (Lot 41341701, Roche, Mannheim, Germany) according to the manufacturer's instructions. In a final volume of $20 \mathrm{~mL}$ reaction mix per sample, the following mixtures was added: 1X FastStart DNA Master Mix, 2 mM MgCl2, 0.2 mM LightSNP HybProbe (Roche 03003248001) appropriate amount of PCR grade water and $500 \mathrm{ng}$ DNA sample. The plates were sealed and centrifuged at 3000 rpm for 1 minute. CES1 SNP rs8192950 was genotyped using a Roche Light Cycler 480 (Roche, Mannheim, Germany) real-time PCR platform and melting curve analyses were performed by the Carousel-Based System PCR program.

\section{Statistical Analysis}

The Statistical Package for Social Sciences (SPSS) version 20 (IBM Corp.; Armonk, NY, USA) was used for statistical analysis. Hardy-Weinberg equilibrium (HWE) analysis was performed using the Chi-square $\left(\mathrm{X}^{2}\right)$ test for the analysis of genotype frequencies. According to the results of the statistical evaluation, a value of $\mathrm{p}<0.05$ was considered statistically significant. The un-paired t test method was used to compare pharmacokinetic parameters with alleles. The relationship between side effects and genotypes was performed using the $x^{2}$ test.

\section{RESULTS}

\section{Clinical Study Results}

Seven patients who received a routine standard chemotherapy regimen including capesitabine in the Acibadem Maslak Hospital Oncology Clinic were enrolled in this study. $71 \%$ of the patients were female and $29 \%$ of them were male. $43 \%$ of the patients were treated for breast cancer and $57 \%$ of them were treated for colon cancer. The mean age of the patients was $55 \pm 16$ years. Each patient enrolled in the study received capecitabine at 1000-1250 $\mathrm{mg} / \mathrm{m}^{2}$, perorally twice daily for 14 days. Patients were routinely examined at the end of the first cycle of treatment by a clinician. While diarrhea and nausea - are dose-limiting side effects - were

\section{Table 2. Pharmacokinetic parameters (mean) of capecitabine}

\begin{tabular}{|c|c|c|c|c|c|c|}
\hline & $C_{\max }(\mu \mathrm{g} / \mathrm{mL})$ & $k_{e l}\left(h^{-1}\right)$ & $t_{1 / 2}(h)$ & $A U C_{0-4 h}(\mu \mathrm{g} \cdot \mathrm{h} / \mathrm{mL})$ & $A U C_{4 h-~}(\mu \mathrm{g} . \mathrm{h} / \mathrm{mL})$ & $A U C_{\text {total }}(\mu \mathrm{g} . \mathrm{h} / \mathrm{mL})$ \\
\hline$\overline{\mathrm{x}}$ & 3.19 & 0.46 & 2.98 & 4.60 & 3.18 & 7.77 \\
\hline SD & 2.53 & 0.27 & 3.84 & 2.25 & 3.86 & 4.42 \\
\hline
\end{tabular}


Kurtan Yüksel et al. Evaluation of the association of SNP in carboxylesterase enzyme (CES1) with pharmacokinetic and adverse effects of capecitabine in breast and colorectal cancer patients

observed during the first cycle, abdominal pain, stomatitis and hand-foot syndrome were not reported.

The plasma concentration time curve of the capecitabine which was obtained at 0.5, 1, 2, 3 and 4 hours after capecitabine administration are shown in Figure 1.

The $C_{\text {max }}, k_{e e^{\prime}} t_{1 / 2}$ and AUC which were calculated using plasma concentration time curve are shown in Table 2.

A comparison of $\mathrm{AUC}_{\text {total }}$ values of the capecitabine plasma concentrations are shown in Figure 2.

\section{Pharmacogenetic and Pharmacokinetic Study Results}

Statistical evaluation of genotyping analysis for CES1 SNP (rs8192950) was performed as indicated in the relevant section. The expected and observed values of SNP were determined using Hardy-Weinberg Equilibrium. The chi-square $\left(x^{2}\right.$, Chi-square) test was performed to check if genotype frequen-

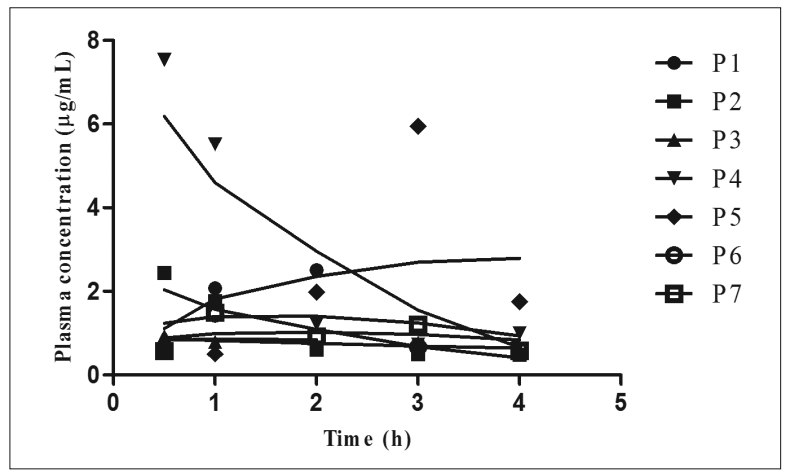

Figure 1. Capecitabine plasma concentration time curve.

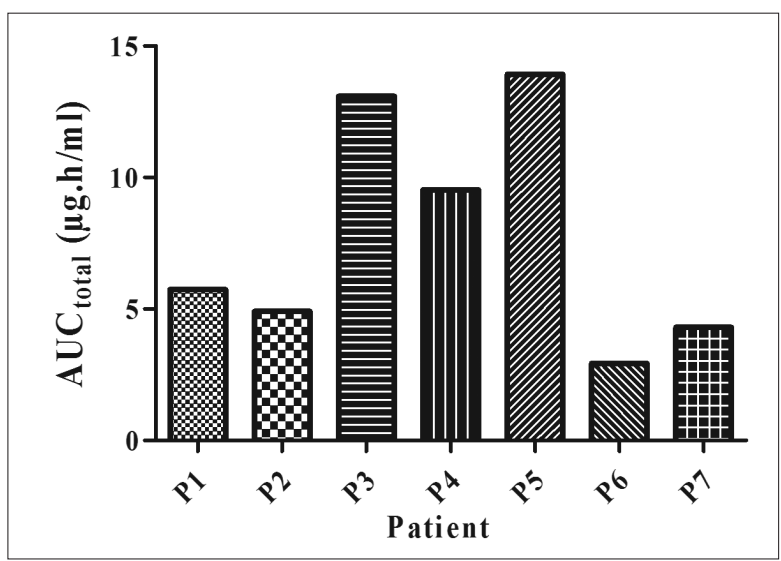

Figure 2. Comparison of $A \cup C_{\text {total }}$ patient values each subject individually in the study group.

P: Patient

Table 3. Statistical evaluation of the selected SNP in CES1

\begin{tabular}{|lccccc|}
\hline SNP & Allele & Observed (n) & Expected & $\mathrm{X}^{2}$ & $\mathrm{p}$ \\
\hline CES1 & $\mathrm{C} / \mathrm{C}$ & 2 & 2.282 & 0.193 & 0.909 \\
& $\mathrm{~A} / \mathrm{A}$ & 1 & 1.288 & & \\
& $\mathrm{~A} / \mathrm{C}$ & 4 & 3.429 & & \\
\hline
\end{tabular}

cies were be in Hardy-Weinberg equilibrium and the statistical test indicated that all variants within the population were in Hardy-Weinberg equilibrium (Table 3).

Heterozygotes (A/C) were observed in 4 of the 7 patients (57\%) and wild type (C/C) were observed in 2 of the 7 patients (29\%). CES1 gene mutation (A/A) was only detected in one patient (14\%). The allele and allele frequencies that cause a change in enzyme activity in the CES1 gene are shown in Figure 3.

The mean $\mathrm{AUC}_{0-4 \mathrm{~h}}$ of the five heterozygote and mutant rs8192950 allele carriers was $5.11 \pm 1.11 \mu \mathrm{g} . \mathrm{h} / \mathrm{mL}$, the mean $\mathrm{AUC}_{0-4 \mathrm{~h}}$ of the two non-carriers was $3.29 \pm 0.6 \mu \mathrm{g} . \mathrm{h} / \mathrm{mL}$ (Table 4). The mean AUC values of the mutant and heterozygote patients were 1.5 times more than the AUC values of the wild type. However, no statistically significant differences between CES1 gene mutation ( $r$ 8192950) and AUC values ( $p=0.2236)$ were observed (Figure 4).

The relationship between side effects and CES1 gene mutation (rs8192950) was performed using chi-square ( $X^{2}$, Chi-square) test. No statistically significant differences between genotypes and the most frequently observed side effects of diarrhea $(p=0.1028)$, asthenia $(p=0.6456)$, anemia $(p=0.6456)$, emesis $(p=0.3499)$ were observed.

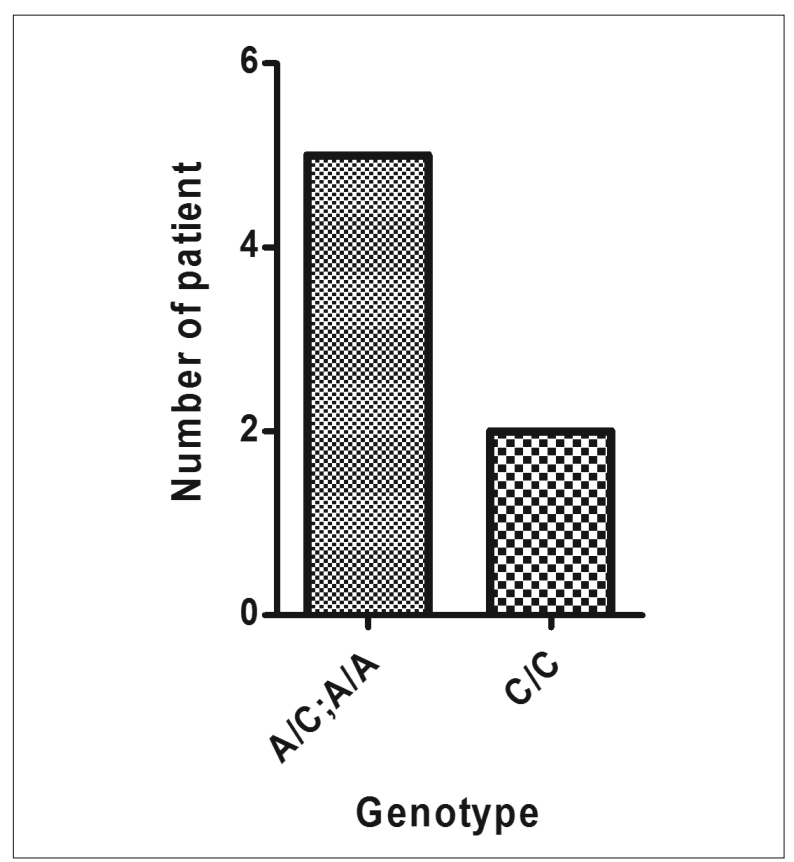

Figure 3. Alleles and allele frequencies of CES1 gene in the study population given as numbers.

\section{Table 4. Statistical analysis for the relationship between CES1 (rs8192950) genotypes and pharmacokinetics of genotypes}

\begin{tabular}{|lcccc|}
$\begin{array}{l}\text { CES1 } \\
\text { (rs8192950) }\end{array}$ & $\mathrm{N}$ & $\begin{array}{c}\mathrm{AUC}_{0-4 h} \\
\text { ( } \mu \mathrm{g} \cdot \mathrm{h} / \mathrm{mL} \text { ) }\end{array}$ & SE & $\mathrm{p}$ \\
\hline A/C;A/A & 5 & 5.11 & 1.11 & 0.2236 \\
C/C & 2 & 3.29 & 0.61 & \\
AUC0-4h as a mean; SE: standard error. & & \\
\end{tabular}




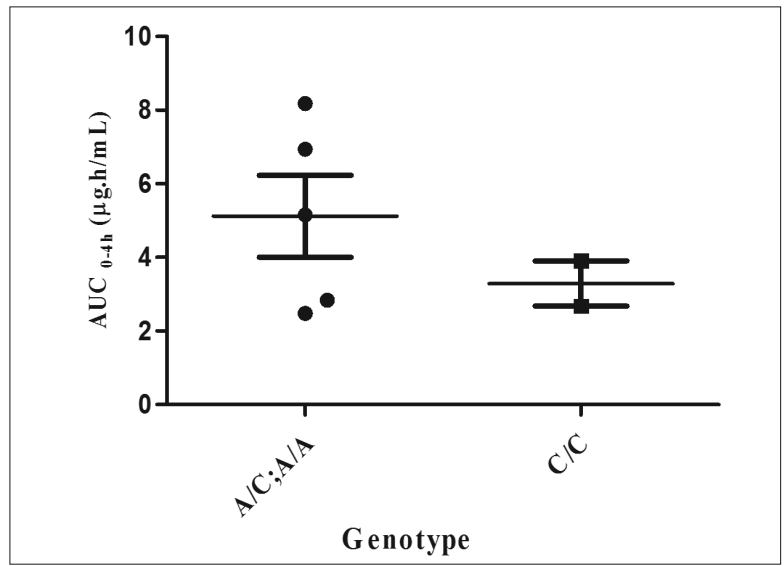

Figure 4. Boxplot showing $\mathrm{AUC}_{0-4 h}$ values for each variants of CES1 (rs8192950) (•) indicate AUC0-4h of each subject individually in the subgroup.

\section{DISCUSSION}

Capecitabine is a tumor-selective fluoropyrimidine carbamate, an oral prodrug of 5-FU. Capecitabine is used orally in the treatment of breast, colorectal and gastric cancer. 5-FU is one of the oldest and the most widely used antimetabolite and cytotoxic agents. 5-FU, which is responsible for the anticancer effect of capecitabine, and capecitabine have narrow therapeutic indices, such as many other antineoplastic agents and high interpatient variability is observed in the pharmacokinetics parameters of capecitabine and its metabolites. Therefore, differences in efficacy and toxicity profile are indicated among individuals (Ribelles et al. 2008). We eveluated the association of SNP in CES1, involved in the metabolism of capecitabine, with pharmacokinetic and adverse effects of capecitabine in breast and colorectal cancer patients and demonstrated the effect of interindividual differences.

A routine standard chemotherapy regimen of 1000-1250 mg/ $\mathrm{m}^{2}$, perorally twice daily for 14 days followed by a 7-day rest period, was applied to the patients. Large interpatient variability in the pharmacokinetics of capecitabine was observed despite body surface area based dosing (Rudek et al. 2013). The mean $\mathrm{AUC}_{0-4 \mathrm{~h}}$ of the capecitabine for the seven patients was $4.60 \pm 2.25 \mu \mathrm{g} . \mathrm{h} / \mathrm{mL}$, which was similar to previous findings. After oral administration, capecitabine was rapidly absorbed from the gastrointestinal tract and reached peak plasma concentrations at approximately 0.3-3 hours. While the $C_{\max }$ of capecitabine is $4.47 \mathrm{mg} / \mathrm{mL}$ (Xeloda Roche 500 mg Summary of Product Characteristics; Rudek et al. 2013), in our study, the $C_{\max }$ of capecitabine was $3.19 \pm 2.5 \mu \mathrm{g} / \mathrm{mL}$.

The observed $A \cup C_{\text {total }}$ value of capecitabine in our study was highly variable between patients, but it was similar to previous findings (27-89\%). The reason for differences in the pharmacokinetics of the capecitabine among individuals was different expression of enzymes involved in the metabolism (Lam et al. 2016). Capecitabine is metabolized to 5-FU by three-step enzymatic pathways. It is converted into $5^{\prime}$-DFCR in the liver by CES. The $5^{\prime}$-DFCR is then converted to $5^{\prime}$-DFUR by CDA which is found in the liver and tumor tissues. 5-FU formation occurs on the tumor area with the basis of TYMP (Thorn et al. 2011; Daniele et al. 2013).
Genetic variation in CES enzymes may lead to changes in the inactivation of drugs and activation of prodrugs and contribute to adverse drug reaction and/or increased sensitivity/resistance to drug treatment. The majority of variations at the DNA level (over 90\%) are in the form of single-nucleotide polymorphisms (Langmann et al. 1997; Kim et al. 2003; Marsha et al. 2004). The SNP rs8192950 in CES1, which has a mutation frequency of approximately $64 \%$ in the European population, was selected in this study. The mutation of rs8192950 in CES1 is considered an association with a decreased CES1 enzyme activity. It has been asserted that the mutation of CES1 rs8192950 decreases CES1 enzyme activity, resulting in more clopidogrel to be converted into active metabolites and was associated with the decreased recurrence of ischemic events (Zhao et al. 2016).

The mean $\mathrm{AUC}_{0-4 \mathrm{~h}}$ of the four heterozygote $(\mathrm{A} / \mathrm{C})$ and mutant (A/A) rs8192950 allele carriers is $5.11 \pm 1.1 \mu \mathrm{g} . \mathrm{h} / \mathrm{mL}$, the mean $A \cup C_{0-4 h}$ of the two non-carriers (C/C) is $3.29 \pm 0.6 \mu \mathrm{g} . \mathrm{h} / \mathrm{mL}$. The mean $A \cup C_{0-4 h}$ values of the mutant and heterozygote patients were 1.5 times higher than the $A \cup C_{0-4 h}$ values of the wild type. However, no statistically significant differences between the CES1 gene mutation (rs8192950) and the AUC values were observed $(p=0.2236)$. This is the first study in which the relationship between CES1 rs8192950 mutation and pharmacokinetics of capecitabine has been indicated.

Dose limiting toxicities of capecitabine include diarrhoea, abdominal pain, nausea, stomatitis and hand-foot syndrome (Reigner et al. 2001). At the end of the first cycle, the most frequently observed side effects were diarrhea, asthenia, anemia, emesis; however hand-foot syndrome, stomatitis were not reported in our study. No statistically significant differences between genotypes and the most frequently observed side effects were observed. The low number of patients in our study is the most important reason for the lack of statistical significance between genotypes and observed side effects.

Some previous studies have evaluated the association of SNPS in CES, involved in the metabolism of capecitabine, with efficacy and toxicity. Hamzic et al. (2017) evaluated the association of genetic variability in CES1 and CDA in 144 patients treated with capecitabine. CES1 c.690+129delC (rs3217164) and c.116541C>T (rs2244614) was revealed as significantly associated with overall capecitabine toxicity. This is the first study identifying an association of genetic variation in CES1 with capecitabine related toxicity (Hamzic et al. 2017). In contrast, Pellicer et al. (2017) conducted a study in which 23 selected SNPs in 8 enzymes (CDA, DPD, ENOSF1, CES1, TYMS, SLC22A7, TYMP, UMPS) were analyzed in 301 colorectal cancer patients treated with capecitabine-based chemotherapy. No association was reported between CES1 SNPs and the risk of capecitabine related toxicity (Pellicer et al. 2017). Therefore, additional studies are required to support the association of genetic variation in CES1 with the efficacy and toxicity of capecitabine, and the results will need to be confirmed by larger studies.

\section{CONCLUSION}

Based on the results of our study, no statistically significant differences between CES1 gene mutation (rs8192950) and 
AUC $_{\text {total }}$ values and the most frequently observed side effects were observed. As mentioned above, the low number of enrolling patients in our study may be the cause of the lack of statistically significant differences. This correlation could not be completely revealed in most of the published research regarding the association between efficacy and toxicity of capecitabine and other substrate drugs with SNPs in CES1 enzyme. Therefore, additional study in larger groups of patients is required to support our study. In conclusion, this is the first study evaluating an association of genetic variation in CES1 (rs8192950) with pharmacokinetic and adverse effects of capecitabine. Our study will offer an insight into the pharmacogenetic researches to personalized chemotherapy and will provide basic knowledge to related studies.

Ethics Committee Approval: Ethics committee approval was received for this study from the Ethics Committee of Acibadem University Hospitals (ATADEK), Istanbul, Turkey (No: ATADEK 2015/9).

Informed Consent: Written informed consent was obtained from all patients in this study.

Peer-review: Externally peer-reviewed.

Author Contributions: Concept - Z.P.K., M.K.Y., T.K.; Design - Z.P.K., M.K.Y.; Supervision - Z.P.K.; Resource - Z.P.K., A.A.T., T.K; Materials - Z.P.K., A.A.T., T.K., G.Ö.; Data Collection and/or Processing - M.K.Y., Z.P.K., A.A.T., T.K.; Analysis and/or Interpretation - M.K.Y., D.Ö., E.Ö., Z.P.K., T.K.; Literature Search - Z.P.K., M.K.Y.; Writing - Z.P.K., M.K.Y.; Critical Reviews - Z.P.K., G.Ö., A.O.

Conflict of Interest: The authors have no conflicts of interest to declare.

Financial Disclosure: The present work was supported by the Research Fund of Istanbul University (Project No. 57708).

\section{REFERENCES}

- Daniele G, Gallo M, Piccirillo C, Giordano P, D’Alessio A, Del Giudice A, La Porta ML, Perrone F, Normanno N, De Luca A (2013). Pharmacokinetic evaluation of capecitabine in breast cancer. EXpert Opin Drug Metab Toxicol 9: 225-235. [CrossRef]

- Farkouh A, Ettlinger D, Schueller J, Georgopoulos A, Scheithauer W, Czejka M (2010). A rapid and simple HPLC assay for quantification of capecitabine for drug monitoring purposes. Anticancer Res 30: 5207-5211.

- $\quad$ Geshi E, Kimura T, Yoshimura M, Suzuki H, Koba S, Sakai T, Saito T, Koga A, Muramatsu M, Katagiri T (2005). A single nucleotide polymorphism in the carboxylesterase gene is associated with the responsiveness to imidapril medication and the promoter activity. Hypertens Res 28: 719-725. [CrossRef]

- Hamzic S, Kummer D, Milesi S, Mueller D, Joerger M, Aebi S, Amstutz U, Largiader CR. (2017) Novel Genetic Variants in Carboxylesterase 1 Predict Severe Early-Onset Capecitabine-Related Toxicity. Clin Pharmacol Ther 102: 796-804. [CrossRef]

- $\quad$ Kim SR, Nakamura T, Saito Y, Sai K, Nakajima T, Saito H, Shirao K, Minami H, Ohtsu A, Yoshida T, Saijo N, Ozawa S, Sawada J (2003). Twelve novel single nucleotide polymorphisms in the CES2 gene encoding human carboxylesterase 2 (hCE-2). Drug Metab Pharmacokinet 18: 327-332. [CrossRef]

- Lam SW, Guchelaar HJ, Boven E (2016). The role of pharmacogenetics in capecitabine efficacy and toxicity. Cancer Treat Rev 50: 9-22. [CrossRef]
Langmann T, Becker A, Aslanidis C, Notka F, Ullrich H, Schwer H, Schmitz G (1997). Structural organization and characterization of the promoter region of a human carboxylesterase gene. Biochim Biophys Acta 1350: 65-74. [CrossRef]

Lewis JP, Horenstein RB, Ryan K, O'Connell JR, Gibson Q, Mitchell BD, Tanner K, Chai S, Bliden KP, Tantry US, Peer CJ, Figg WD, Spencer SD, Pacanowski MA, Gurbel PA, Shuldiner AR (2013). The functional G143E variant of carboxylesterase 1 is associated with increased clopidogrel active metabolite levels and greater clopidogrel response. Pharmacogenet Genomics 23: 1-8. [CrossRef] Marsha S, Xiao M, Yu J, Ahluwalia R, Minton M, Freimuth RR, Kwok PY, McLeod HL (2004). Pharmacogenomic assessment of carboxylesterases 1 and 2. Genomics 84: 661-668. [CrossRef]

- Paré G, Eriksson N, Lehr T, Connolly S, Eikelboom J, Ezekowitz MD, Axelsson T, Haertter S, Oldgren J, Reilly P, Siegbahn A, Syvanen AC, Wadelius C, Wadelius M, Zimdahl-Gelling H, Yusuf S, Wallentin L (2013). Genetic Determinants of Dabigatran Plasma Levels and Their Relation to Bleeding. Circulation 127: 1404-1412. [CrossRef] Pellicer M, García-González X, García Ml, Robles L, Grávalos C, García-Alfonso P, Pachón V, Longo F, Martínez V, Blanco C, Iglesias I, Sanjurjo M, López-Fernández LA (2017). Identification of new SNPs associated with severe toxicity to capecitabine. Pharmacol Res 120: 133-137. [CrossRef]

- Reigner B, Blesch K, Weidekamm E (2001). Clinical Pharmacokinetics of Capecitabine. Clin Pharmacokinet 40: 85-104. [CrossRef] Ribelles N, Lopez-Siles J, Sanchez A, Gonzalez E, Sanchez MJ, Carabantes F (2008). A Carboxylesterase 2 Gene Polymorphism as Predictor of Capecitabine on Response and Time to Progression. Curr Drug Metab 9: 336-343. [CrossRef]

- Rudek MA, Connolly RM, Hoskins JM, Garrett-Mayer E, Jeter SC, Armstrong DK, Fetting JH, Stearns V, Wright LA, Zhao M, Watkins SP Jr, McLeod HL, Davidson NE, Wolff AC (2013) Fixed-dose capecitabine is feasible: results from a pharmacokinetic and pharmacogenetic study in metastatic breast cancer. Breast Cancer Res Treat 139: 135-143. [CrossRef]

Siegel RL, Miller KD, Jemal A (2019). Cancer statistics, 2019. CA Cancer J Clin 69: 7-34. [CrossRef]

- Tarkiainen EK, Backman JT, Neuvonen M, Neuvonen PJ, Schwab M, Niemi M (2012). Carboxylesterase 1 polymorphism impairs oseltamivir bioactivation in humans. Clin Pharmaco/ Ther 92: 68-71. [CrossRef] Tarkiainen EK, Tornio A, Holmberg MT, Launiainen T, Neuvonen PJ, Backman JT, Niemi M (2015). Effect of carboxylesterase 1 c.428G > A single nucleotide variation on the pharmacokinetics of quinapril and enalapril. Br J Clin Pharmaco/ 80: 1131-1138. [CrossRef]

- TC Ministry of Health General Directorate of Public Health (2018) Turkey Cancer Statistics 2015. Ankara: TC Ministry of Health General Directorate of Public Health. Access 26.10.2018, https:// hsgm.saglik.gov.tr/depo/birimler/kanser-db/istatistik/Turkiye_ Kanser_Istatistikleri_2015.pdf.

- $\quad$ Thorn CF, Marsh S, Carrillo MW, McLeod HL, Klein TE, Altman RB (2011). PharmGKB summary: fluoropyrimidine pathways. Pharmacogenet Genomics 21: 237-242. [CrossRef]

- Turkish Medicines and Medical Devices Agency (TiTCK) (2002, May) Xeloda Roche 500 mg Summary of Product Characteristics. Access 20.11.2017.

- Wang D, Zou L, Jin Q, Hou J, Ge G, Yang L (2018). Human carboxylesterases: a comprehensive review. Acta Pharm $\operatorname{Sin} B$ 8: 699-712. [CrossRef] Xiao FY, Luo JQ, Liu M, Chen BL, Cao S, Liu ZQ, Zhou HH, Zhou G, Zhang W(2017). Effect of carboxylesterase 1 S75N on clopidogrel therapy among acute coronary syndrome patients. Sci Rep 7: 7244. [CrossRef]

Zhao Z, Li X, Sun S, Mei S, Ma N, Miao Z, Zhao M, Peng S (2016). Impact of genetic polymorphisms related to clopidogrel or acetylsalicylic acid pharmacology on clinical outcome in Chinese patients with symptomatic extracranial or intracranial stenosis. Eur J Clin Pharmacol 72: 1195-1204. [CrossRef] 